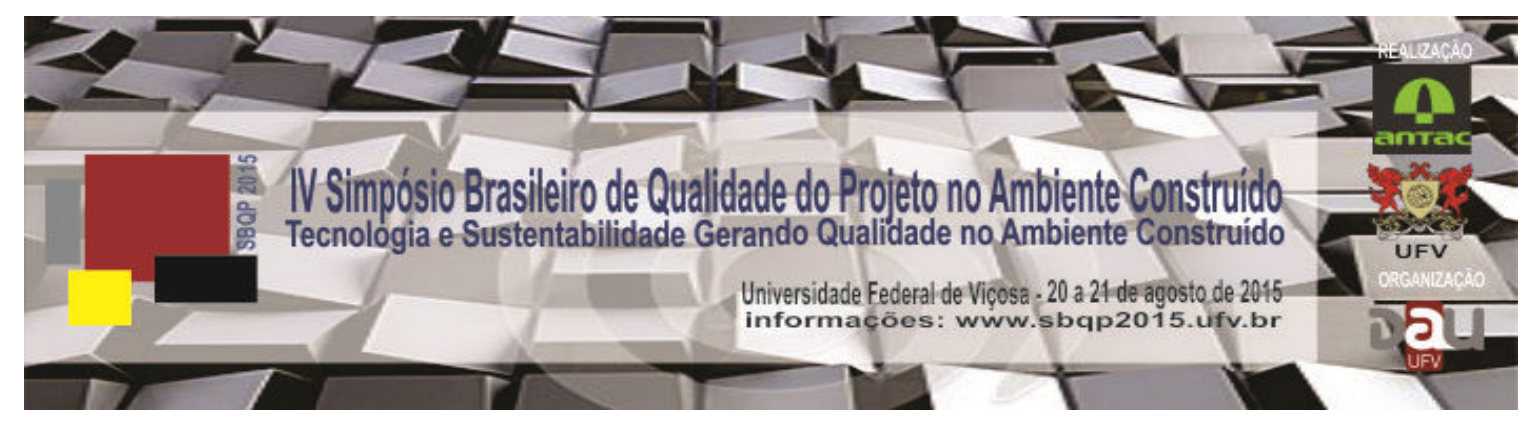

\title{
O USO DE SISTEMA PRÉ-FABRICADO E O PROCESSO DE PROJETO: UMA EXPERIÊNCIA DIDÁTICA ${ }^{1}$
}

\author{
ALBUQUERQUE, Glauce Lilian Alves de \\ UFRN, glauce.lilian@gmail.com \\ ELALI, Gleice V. A. \\ UFRN, gleiceae@gmail.com
}

\begin{abstract}
RESUMO
O foco do estudo foi um experimento didático no campo do projeto arquitetônico de espaços produzidos a partir de sistemas construtivos pré-fabricados desmontáveis e o processo de sua concepção. Por meio da observação dos espaços gerados, buscouse investigar o modo como os estudantes do $6^{\circ}$ período do curso de Arquitetura e Urbanismo lidam com projetos concebidos a partir da adoção de um sistema construtivo pré-fabricado desmontável, de modo a contribuir para a compreensão dos elementos essenciais ao ensino desse tipo de projeto. Para tanto foi desenvolvida uma pesquisa exploratória com base em multimétodos que abrangeu: análise documental, visitas técnicas e exercício acadêmico, todos documentados por imagens. Embora o estudo não seja conclusivo, notou-se quem apesar de terem obtido um desempenho adequado, os estudantes apresentaram alguma dificuldade para acessar os recursos a eles disponibilizados. Além disso, o exercício evidenciou que - uso de um sistema pré-fabricado desmontável/portável alterou a valorização/hierarquização dos condicionantes projetuais durante o processo projetual, uma vez que, diferentemente do que acontece em disciplinas tradicionais, os 'estudantes-projetistas' demonstraram maior preocupação com as questões construtivas, sobretudo os elementos estruturais (apoios e cobertura), em detrimento de funcionalidade, estética e características físicas do local.
\end{abstract}

Palavras-chave: Processo de Projeto, Arquitetura Efêmera, Experiência Didática.

\begin{abstract}
The focus of the study was a teaching experiment in architectural design of spaces produced from portable prefabricated systems and the process of its design. By observing the spaces generated, we sought to investigate how architecture students of the 6th Architecture and Urbanism course of the period deal with projects designed from the adoption of a prefabricated demountable building system, in order to contribute to the understanding of essential elements to teaching this kind of project. Thus, we developed an exploratory research based on multimethod covering: document analysis, technical visits and academic exercise, all documented by pictures. Although the study is not conclusive, it was noted who despite having
\end{abstract}

\footnotetext{
${ }^{1}$ Trabalho apresentado no IV SBQP 2015. Universidade Federal de Viçosa. Disponível em: doi> http://dx.doi.org/10.18540/2176-4549.6030
} 
obtained adequate performance, the students presented some difficulty to access the resources available to them. In addition, the exercise showed that the use of a prefabricated removable / portable system changed the recovery / hierarchy of projective constraints during the design process, since, unlike what happens in traditional disciplines, the 'student-designers' show greater focus on constructive issues, especially the structural elements (support and coverage), at the expense of functionality, aesthetics and physical characteristics of the site.

Keywords: Design Process, Ephemeral Architecture, Teaching Experience.

\section{INTRODUÇÃO}

O presente artigo se refere a um exercício projetual realizado com estudantes de arquitetura ( $6^{\circ}$ período), cujo objetivo foi investigar o modo como eles lidam com o processo de projetos concebido a partir da adoção de um sistema construtivo pré-fabricado remontável, bem como, entender de que forma acontece o gerenciamento do processo de projetação por parte destes alunos ao se depararem com limitações inerentes ao uso do sistema e seu rebatimento no projeto.

Esta experiência aconteceu na disciplina Projeto de Arquitetura de Sistemas Construtivos Industrializados regularmente oferecida pelo curso de Arquitetura e Urbanismo da Universidade Potiguar (UnP) e tinha como enfoque a capacitação do aluno para o desenvolvimento de uma proposta arquitetônica que exigisse a aplicação de um sistema construtivo préfabricado. A disciplina foi ministrada simultaneamente em 03 (três) turmas, para um total de 52 estudantes: 6MA (17 alunos), 6MB (17 alunos) e 6MC (18 alunos) durante o período de 2011.2, em todos os casos envolvendo o mesmo docente.

Destaca-se o papel inovador dessa proposta no contexto do curso, uma vez que o exercício acadêmico consistiu na simulação de uma situação real, em que os alunos projetaram usando um produto disponível no mercado local.

Para explanar a experiência realizada esse paper está subdividido em 05 partes: considerações sobre o processo projetual; conhecendo o sistema adotado; descrição da experiência didática realizada; o resultado do experimento, sob o ponto de vista do professor; considerações finais.

\section{CONSIDERAÇÕES SOBRE O PROCESSO PROJETUAL}

O ato de projetar corresponde a um processo dinâmico de ordenação da forma em detrimento do programa e de outros condicionantes, como a funcionalidade, a forma plástica, as condições de conforto ambiental e as exigências tecnológicas adequadas à solução do problema.

Considerando a possibilidade de resolução de um "problema" como ponto de partida da concepção projetual, o projetar pode ser entendido como um processo de tomada de decisões (BOUTINET, 2002; NAVEIRO, 2001; KRAUSE, 1998). Sob esse ponto de vista, a concepção arquitetural passaria, assim, pela (inevitável) problematização de uma questão complexa, de modo que somente a partir da definição preliminar de um conjunto de soluções possíveis a ideia inicial do projeto arquitetônico seria delineada. Por outro lado, como o projeto arquitetônico exige conhecimentos sobre diversas áreas, domínio sobre representação e, também criatividade (CORDIVIOLA, 2001), ele pode ser 
considerado uma síntese dos muitos saberes (ZEIN, 2003), e um modo de promover sua estruturação sistemática.

Portanto, a elaboração de um projeto de arquitetura exige a combinação de uma série de requisitos que não podem ser esquecidos, pois compreendem a formalização de condições e necessidades que norteiam as decisões do projetista e são anteriores à proposição projetual. Entre os elementos que limitam ou condicionam o projeto, direcionando o processo de sua elaboração, estão: as condições climáticas e físicas do terreno/local em que a obra será inserida, a legislação urbanística, o dimensionamento de ambientes, as necessidades do cliente, os aspectos socioculturais, os materiais (e mão de obra) disponíveis, o sistema construtivo, as normas técnicas, os recursos financeiros existentes, os elementos estéticos, e até mesmo o repertório projetual do autor.

Assim, é possível dizer que o projeto arquitetônico se derivaria da seleção e ordenação desses condicionantes (ODEBRECHT, 2006; NEVES, 1998), correspondendo à busca por alternativas de solução para uma determinada questão, considerando suas muitas nuances (SILVA, 1998). Para tanto, um passo decisivo é a adoção do partido, momento em que o projetista esboça sua solução para a complexa equação que a ele se apresenta.

A partir da identificação de um problema básico ou do programa de necessidades (definido pelo projetista e seu cliente), o arquiteto identifica os condicionantes que podem influenciar ou (de)limitar suas decisões, a fim de definir qual o caminho a seguir no processo de projetação. Como essa definição pressupõe uma síntese das principais ideais ligadas à fase conceptual (ZEIN, 2003), uma parte importante do produto imaginado muitas vezes é resultante da hierarquização dos condicionantes projetuais. A forma plástica, por exemplo, pode ser influenciada pela topografia local, pela funcionalidade exigida no programa (casos em que o zoneamento e a implantação sejam fundamentais para as decisões arquitetônicas), pela estrutura, pelos materiais, pelas condições de insolação das fachadas, e assim por diante, em função dos enfoques que se mostrem decisivos para as escolhas do projetista.

Após a definição do partido acontecem os estudos preliminares, desenvolvidos de acordo com a natureza do projeto, e as experiências pessoais do projetista, representando a ideia. Geralmente, além de diagramas e gráficos que nortearão a solução projetual, o arquiteto recorre a esboços (desenhados à mão livre ou em programas computacionais de modelagem) e a simulações (como as maquetes volumétricas, físicas ou virtuais). Nesse sentido, as ferramentas computacionais quando dominadas pelo projetista, podem ser utilizadas não apenas para a finalização gráfica do projeto, mas, principalmente auxiliar na elaboração do mesmo desde sua fase inicial.

\section{CONHECENDO O SISTEMA ADOTADO}

O sistema escolhido foi projetado por uma empresa multinacional, com sede no norte da Itália, empresa esta que projeta e fabrica todas as peças dos sistemas que comercializa. Dentre os modelos disponíveis nos catálogos (www.sprech.com/, acessado em agosto de 2011), optou-se por um sistema em forma de arcos e que permitisse sua relocação constante, através de encaixes remontável. Contudo, por questões éticas e para facilitar a 
compreensão deste paper, trataremos por SCR o sistema adotado neste experimento.

Embora outras opções parecessem igualmente adequadas à simulação projetual, o sistema escolhido se mostrou mais convidativo ao estudante, por 'fugir' do padrão das tendas com plantas quadradas e de cobertura piramidal (em 04 águas), com o entendimento que suas curvas trariam muitas possibilidades de composição plástica. Este sistema apresenta sua forma em arco, cuja estrutura modular ortogonal (quadrado e retangular) possui dimensões que variam de 5,00m x 5,00m (para planta em formato quadrado), e de 8,00 a 10,00m $\times 5,00 m$ (para planta em formato retangular).

Além das informações básicas sobre o sistema SCR, apresenta dados técnicos referentes às cores para estrutura e para a lona, e a elementos opcionais que permitem ajustes, tais como vedações, acréscimo de janelas, pisos móveis, uso adequação do vidro e/ou do policarbonato, elementos destinados a instalações (hidrossanitárias/pluviais/elétricas) e eventual climatização.

O sistema SCR dispõe de 03(três) modelos/módulos, sendo todos eles feitos em estrutura metálica em aço galvanizado e alumínio, incluindo suas peças de encaixes, e a cobertura em material plástico tipo lona (PVC). Independente do módulo, todos os modelos utilizam a forma curva como referência visual de volumetria, sendo o 'arco' o elemento padrão de estruturação da tensoestrutura. Os modelos disponíveis (Figura 01) são conhecidos como Cruciforme, Arco Túnel e Gaivota.

Figura 01: Modelos disponíveis (cruciforme, arco túnel e gaivota)

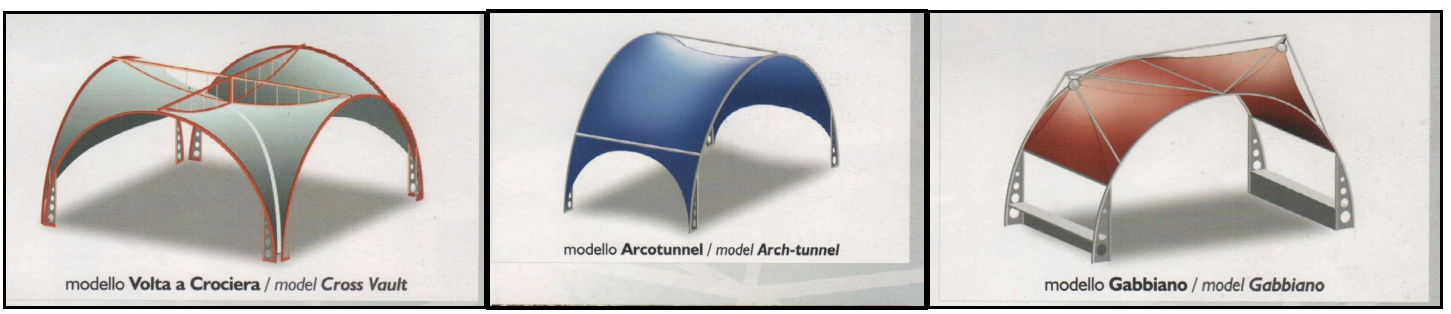

Fonte: www.sprech.com (Acesso em 08 de Agosto de 2014)

\section{A EXPERIÊNCIA}

Os estudantes foram divididos em grupos (03 a 04 membros) que, durante 0 semestre, desenvolverem o anteprojeto de um espaço comercial contendo um edifício permanente (mercado) e uma instalação de caráter efêmero (feira itinerante), esta última utilizando o SCR.

Antes de iniciarem o processo projetual, os alunos receberam uma carga de informações teóricas e técnicas a fim de embasá-los para o exercício, abordando aspectos históricos, conceituais e normativos voltados para espaços comerciais, tendências de projetos contemporâneos e discussão das particularidades dos projetos de feiras livres (com adoção de apostila contendo detalhes e especificidades do tipo de mobiliário usualmente utilizado nesses espaços). Ainda como suporte ao processo projetual foram realizadas visitas técnicas às feiras livres locais, com o intuito de familiarizar os participantes com o uso daquele tipo de espaço e provocar questionamentos sobre os pontos mais significativos de projetos desta natureza. 
O passo seguinte foram aulas elucidativas sobre questões estruturais e sistemas pré-fabricados, com informações adicionais mais aprofundadas sobre adotado, tais como: características do produto (como modelos, dimensões, cores, materiais construtivos, encaixes, elementos adicionais, manutenção e limpeza, durabilidade e vantagens). Complementando o aporte teórico, foram exibidos catálogo técnico, imagens fotográficas e um vídeo com processo de montagem de uma tensoestrutura.

\subsection{A Gestão do Processo Projetivo: o método adotado.}

Ao término da parte teórica inicial os estudantes receberam a sugestão de adoção de um programa de necessidades inicial e as informações gerais sobre os lotes, seguido de visita técnica aos lotes, medições/conferências, levantamento do entorno e estudo das prescrições urbanísticas.

O desenvolvimento do estudo preliminar contou com o acompanhamento do professor através de atendimento em sala de aula, no qual a maioria das dúvidas era sanada por meio de croquis elucidativos, tanto por parte do professor, quanto por parte dos alunos, que geravam discussão e reflexão sobre o processo e o produto a ser obtido.

Para o acompanhamento do processo projetivo, o docente utilizou um caderno de anotações, anotações estas compartilhadas com os alunos através de registro dos principais pontos discutidos e também confirmava os 'vistos'. Os vistos correspondiam a um momento presencial e avaliativo no qual, em uma data estabelecida por eles ao iniciar o processo de projetação, os alunos deveriam apresentar os estudos realizados. A cada encontro, após a discussão realizada entre o docente e os discentes, os alunos assinavam 0 caderno, dando ciência daquilo que fora falado e do que deveriam ajustar em suas propostas (Figura 02). O não cumprimento do visto por parte do grupo, significava que os alunos seriam penalizados com diminuição na nota final relativa ao acompanhamento.

\section{Figura 02: Croquis Esquemáticos de Zoneamento e sobre a Estrutura}

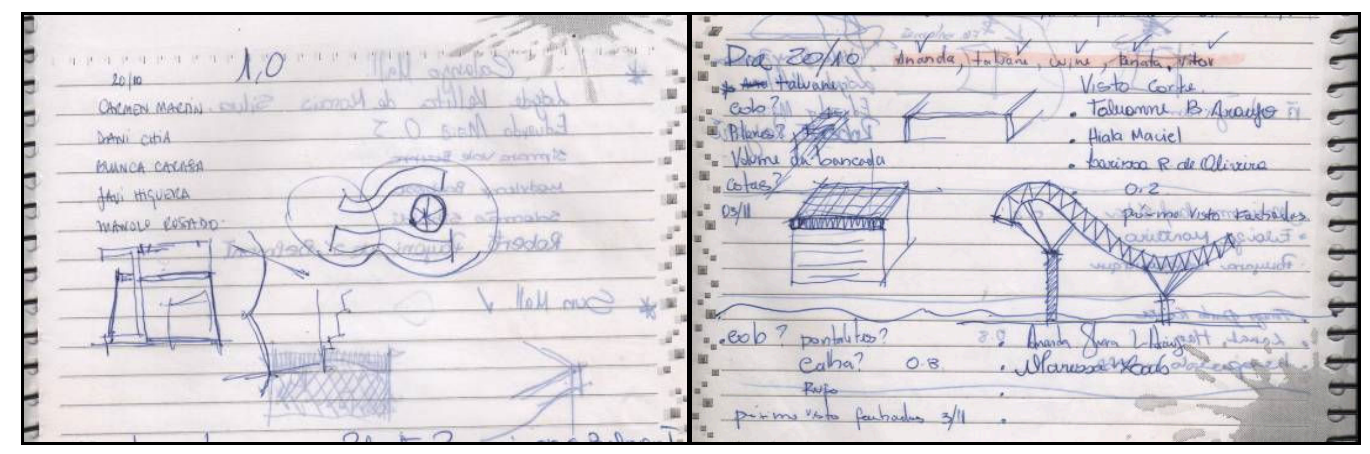

Fonte: Anotações do Professor (ALBUQUERQUE, 2013).

Na primeira etapa projetual, estudo preliminar, os estudantes utilizaram apenas desenhos à mão livre. Na etapa seguinte, o anteprojeto, eles recorreram a programas computacionais como AutoCAD e Sketchup, utilizadas, respectivamente, para representações bidimensionais e tridimensionais.

Ao final do semestre os grupos fizeram apresentações orais para socializar e defender suas propostas, o que proporcionou à turma uma excelente 
oportunidade para trocar conhecimento e apreciar diferentes soluções surgidas pela utilização do mesmo sistema.

\subsection{Análise do Processo Projetivo}

De modo geral observa-se que os estudantes começaram a projetar zoneando o lote escolhido, definindo rapidamente o acesso e localizando o bloco principal, de modo que a área remanescente seria posteriormente dividida entre o espaço da feira e o estacionamento. Em todas as propostas, o espaço voltado à feira foi locado externamente ao edifício principal. Em 15 estudos (de um total de 18) havia um espaço previamente definido para feira que, quando desmontada dará lugar a uma área de lazer ou local para eventos. Ressalte-se, ainda, que nenhuma proposta colocou o espaço da feira em área interna ao mercado ou minimamente delimitada por ele, como aconteceria na adoção de forma de "U" para o prédio permanente.

Em atelier, desde os primeiros traços, o professor discutiu cada estudo com o respectivo grupo proponente, mas claramente não influenciou suas decisões, se limitando a analisar junto aos alunos aquelas soluções consideradas inadequadas, ajudando a aperfeiçoar o desenvolvimento das ideias lançadas.

A maioria dos grupos começou o trabalho fazendo o zoneamento do lote por meio de manchas, sem demonstrar grandes preocupações formais iniciais, sobretudo com relação ao prédio permanente, que aparentou "estar sendo pensado" lentamente, sem definição plástica a priori. De fato, fora observado que no desenvolvimento das propostas os alunos trabalharam primeiro as partes, pouco considerando o todo, situação que corrobora a indicação de Mahfuz (1995), ao indicar que, em geral, as relações estabelecidas entre os componentes de projeto resultam da progressão das partes para o todo. (Figuras 03 e 04)

Figuras 03 e 04: Propostas desenvolvidas pelos alunos concebidas: 'partes' para o 'todo'.

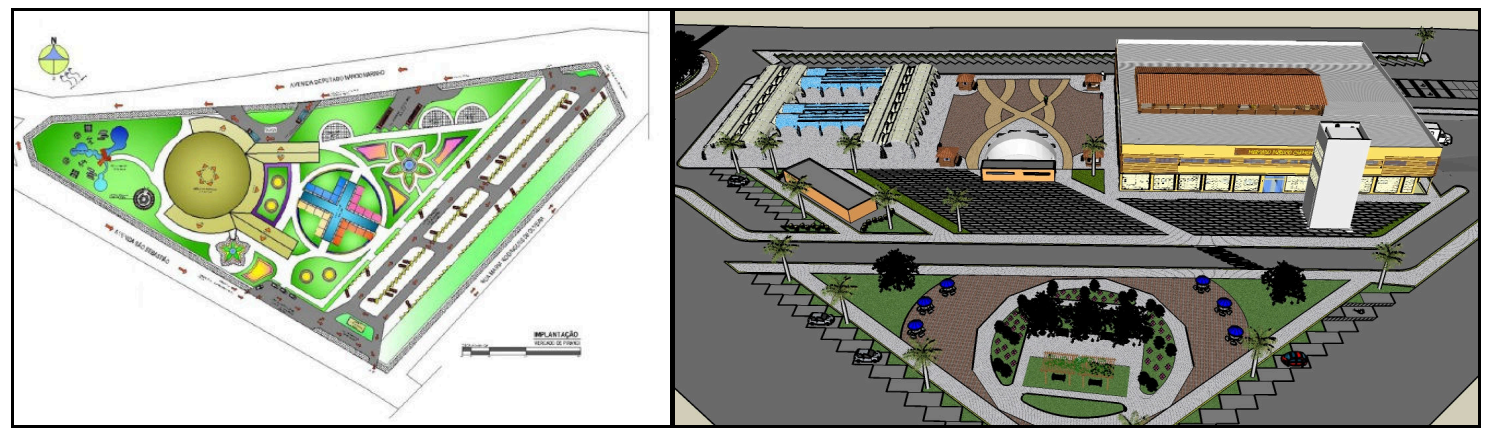

Fonte: ALBUQUERQUE (2013).

$\mathrm{Na}$ continuidade dos trabalhos, também foi observada uma relativa 'segmentação plástica' das propostas, nas quais o edifício (uso permanente) e a edificação desmontável contrastavam entre si, não adotando nem a mesma linguagem formal nem materiais construtivos similares. Alguns estudantes pensaram em buscar no contraste de formas o resultado harmônico para a proposta, com exceção de um pequeno número de propostas que trabalhou a forma plástica das duas edificações como se estas fossem uma só, buscando na ideia do 'todo', a concepção plástica de sua 
proposta, ou seja, tentando definir um conjunto de edificações que se complementassem funcional e visualmente. (Figuras 05 e 06)

Figuras 05 e 06: Propostas desenvolvidas pelos alunos concebidas do 'todo" para as 'partes'.

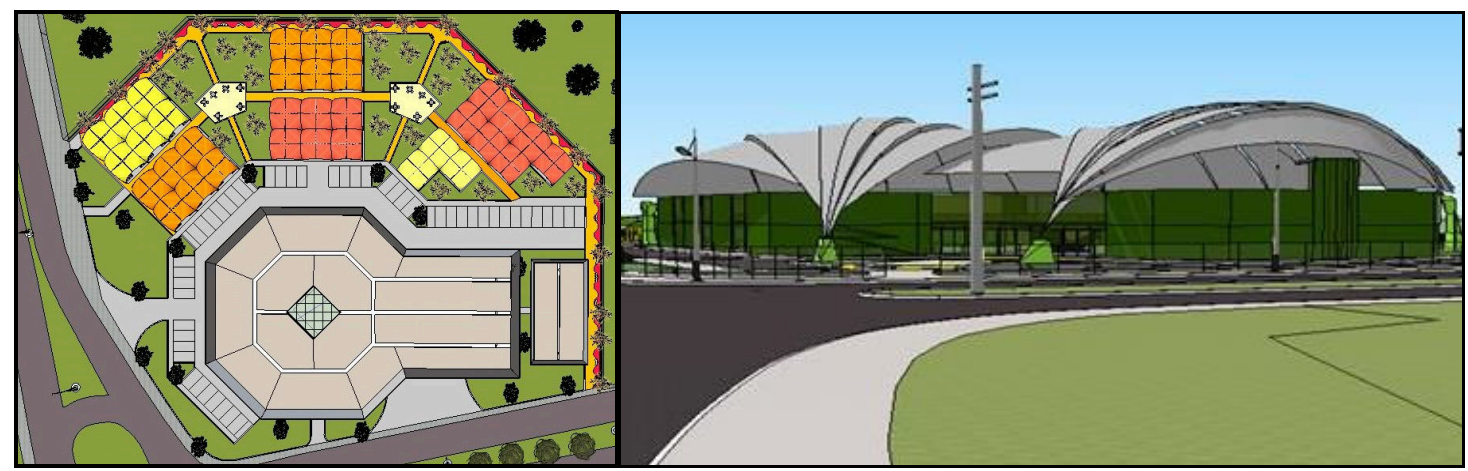

Fonte: ALBUQUERQUE (2013).

Embora a projetação arquitetônica envolva a passagem por etapas, essa prática não é linear ou estática, pois permite muitas idas e vindas entre elas, levando ao projetista adotar vários procedimentos processuais, de acordo com o método projetual escolhido. Este movimento projetivo é percebido na gestão do projeto.

\subsection{Partido Arquitetônico}

Entendendo o partido arquitetônico como a 'essência do projeto' e sua 'ideia formadora', definida com base nos aspectos que impulsionam ou limitam as escolhas arquitetônicas, verificou-se que os estudantes apresentaram propostas diferenciadas, com linguagem contemporânea: (1) um primeiro grupo apresenta soluções que evidenciam a estrutura metálica em sua aparência; (2) um segundo grupo procura dar um toque regionalista à proposta, adotando materiais construtivos, revestimentos e coberturas mais rústicas; (3) um terceiro, ainda, tenta aliar uma arquitetura mais tradicional a elementos inovadores. (Figuras 07, 08 e 09)

Figuras 07, 08 e 09: Exemplos do grupo 1, 2 e 3, respectivamente. 


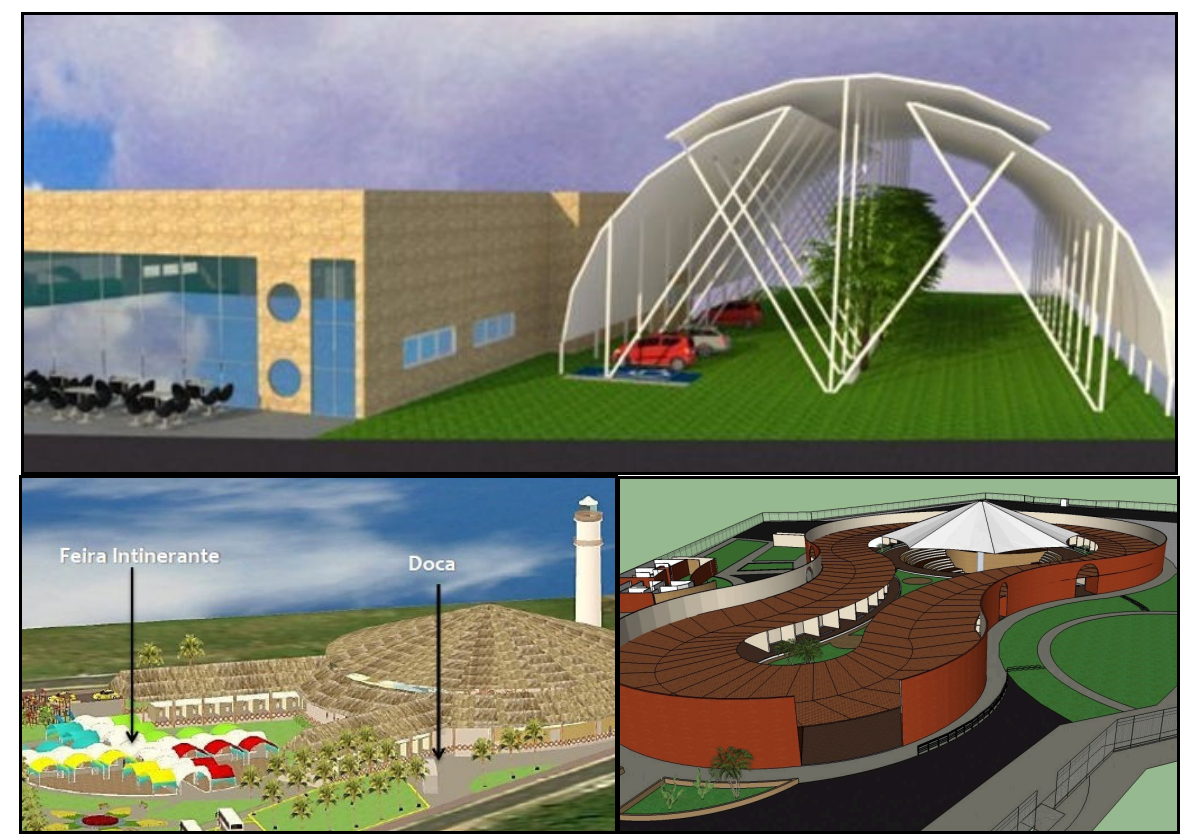

Fonte: ALBUQUERQUE (2013).

Em todos os casos, analisando as propostas sob o olhar de Boudon et al (2000), perceberemos que os alunos priorizaram como ideia central "destacar o edifício maior e mais convencional" que, talvez por ter caráter permanente, aparentava "merecer maior atenção". Nesse sentido, para o edifício permanente os alunos adotaram uma escala diferenciada do entorno (bloco maior e mais alto), enquanto as tendas ajudaram a destacá-los, mantendo-se menores e mais baixas.

A maioria das propostas partiu primeiro pela forma do edifício destinado ao mercado, afinal este era "o prédio que seria permanente", a feira deveria contrastar. Para os estudantes, acostumados a seguir o mesmo processo de projetação para as edificações permanentes, projetar algo que já estava prédefinido era algo novo e diferente. Embora novo, era mais fácil porque o partido da construção desmontável já estava definido, ou seja, parece ter sido mais fácil projetar a parte desmontável pelos alunos,uma vez que a planta com suas dimensões já estabelecidas e seus possíveis encaixes, permitiria adequações com mais rapidez e fluidez projetual, diferente da parte permanente do conjunto arquitônico que necessitaria ser pensada em todos os seus aspectos. Talvez por isso, tenham recebido maior atenção em sua projetação.

De modo geral, como dito antes, no projeto do edifício convencional os estudantes começaram o processo analisando a questão funcional e zoneando minimamente as atividades; em seguida discutiram o volume e lançaram a estrutura de modo a sustentar a coberta e não impedir a funcionalidade pretendida. Organizar o espaço funcionalmente foi a maior prioridade dos alunos nesta fase do processo. Eles partiram da distribuição espacial através da adequação das medidas dos módulos ao terreno, sem se preocupar com a forma, afinal para eles, esta já estaria definida pelo próprio sistema. Na proposta do espaço voltado para a feira os estudantes utilizaram claramente o método Normativo (MAHFUZ, 1995), pois a composição arquitetônica dos projetos partiu da escolha do sistema pré-fabricado, 
tomado como ponto chave da concepção, elemento básico que deveria gerar a imagem final da composição. Neste caso eles começaram escolhendo um (ou mais) módulo, definindo um arranjo que consideram ideal para organizá-los e marcando em planta a estrutura necessária (pilares); em seguida definiram uma espécie de funcionalidade geral (zoneamento de funções), e só ao final do processo realmente definiram os detalhes relacionados a posicionamento das barracas e das circulações internas.

Contudo, mesmo adotando um sistema construtivo diferente para os edifícios convencional e efêmero, a maioria dos grupos optou por utilizar a mesma modulação estrutural para ambos os edifícios. Embora a modulação estrutural ajude na flexibilização dos edifícios, nota-se que a preocupação por parte dos alunos com a flexibilidade só se reflete nas propostas do espaço da feira.

\section{O RESULTADO OBTIDO, SOB O PONTO DE VISTA DO PROFESSOR}

Ao final do exercício de projetação, o docente ressaltou que, embora a possibilidade de utilizar um produto desmontável, de grande durabilidade, adaptável e de boa aparência plástica tenha motivado os alunos, o catálogo técnico do produto merecia um maior detalhamento, pois, mesmo sendo bastante completo se comparado a outros, suas informações disponíveis representam uma fragilidade para a compreensão do sistema. Apesar dessa dificuldade o professor considerou que os alunos assimilaram a experiência de forma positiva.

Com relação ao ensino propriamente dito, o mestre comentou que "o resultado dos projetos dos alunos aponta para mais ganhos do que perdas". A flexibilidade e a modulação presentes no sistema adotado possibilitaram variedade aos arranjos e a definição de layouts, além das composições plásticas mostrarem-se realistas e adequadas. $O$ docente destacou ainda que as propostas apresentadas ficaram interessantes volumetricamente, pois, embora a forma plástica já estivesse pronta, cabia ao aluno compor.

Contudo, um ponto tido como especialmente negativo se refere à dificuldade de representação gráfica das tendas, que por serem curvadas em quase todas as representações e vistas, não foram bem desenvolvidas pelos alunos que reclamavam a falta de blocos prontos no AutoCAD. Outro fator negativo são as limitações do catálogo técnico em termos de detalhamento. Destacase neste exercício em especial a dificuldade de compreensão de como seriam as instalações e tubulações para as bancadas da feira.

Por outro lado, se comparados o processo de ensino de projetação de uma arquitetura convencional com o processo projetivo de um espaço desmontável, o professor aponta muitas semelhanças, afinal para ele, em todas as situações projetuais o arquiteto (ou aprendiz) seguem as mesmas etapas e condicionantes. Por exemplo, cita-se o uso da modulação como base do processo, que, no caso do aluno ele se apresenta como elemento condutor que dará ao projetista os direcionamentos. No caso de um sistema pré-fabricado as medidas moduladas e pré-definidas não são limitações, ao contrário, são norteadores projetuais. Assim como a modulação, ao seu entender, o mestre afirma que a estrutura, por também estar previamente definida, ajudou ao aluno a propor uma cobertura sem grandes preocupações de peso e gravidade. 
De certa forma podemos entender que as impressões iniciais propostas pelo docente ao elaborar este exercício se confirmaram, sobretudo quanto aos aspectos ligados às primeiras decisões projetuais, tais como modulação e flexibilidade. As dificuldades no uso do sistema se relacionaram muito mais à compreensão do catálogo, do que propriamente do sistema, assim como as dificuldades de representação apontaram para uma deficiência no ensino das disciplinas gráficas, e não propriamente ao uso de um sistema préfabricado em si.

\section{CONSIDERAÇÕES FINAIS}

Nota-se que a maioria dos estudantes entende que, a adoção de um mesmo programa de necessidades para as duas categorias de arquitetura (convencional e efêmera) e que propor espaços de uso semelhante, indicaria similaridade nos processos projetuais, mostrando-se ainda pouco amadurecidos. Falta-lhes um olhar crítico sobre o processo projetual que os permita compreender a diferença entre elencar etapas e princípios de projetação e adotar um método conceptual. De certa forma, parece que acreditam que estão "descartando" a ideia da projetação partir da resolução de problemas de funcionalidade, muitas vezes tomando como ponto de partida para as decisões projetuais os aspectos condicionantes e/ou limitantes do projeto, e deixando de perceber que, a própria seleção de soluções oriundas de condicionantes e de limitantes projetuais já compõe a resolução de problemas.

Assim, o experimento permitiu-nos observar que os modelos de ensino aplicados na academia ainda conduzem ao processo de projetação pautado na hierarquização e sistematização dos elementos projetuais partindo da resolução de problemas.

Segundo Lawson (2011), as decisões projetuais seguem um ciclo contínuo que passa pela avaliação, análise e síntese dos elementos avaliados. O arquiteto estabelece os critérios de seleção. No caso do processo projetivo que adota um sistema pré-definido, parte do trabalho de seleção já foi feito anteriormente, na definição do sistema pelos seus projetistas específicos, o que reduz a tarefa a realizar.

A aplicação do exercício aos estudantes possibilitou observar-se o quanto a adoção de um sistema estrutural modulado acrescentou segurança ao seu modo de projetar, talvez devido à redução da quantidade de questões a serem 'pensadas' ao lidar com a proposta - o que pode ser uma experiência positiva para quem está iniciando na área. Por outro lado, ao diminuir-se a complexidade do problema também fora acrescentado o desafio de lidar com o tal sistema, e esse novo "quebra-cabeças" acabou assumindo o foco do trabalho, fazendo com que os demais condicionantes se tornassem menos importantes naquela situação. Assim, mesmo inconscientemente, os estudantes simplificaram ao máximo o processo projetual, limitando-o à adequação (bi e tridimensional) dos módulos ao lote. Ou seja, a aplicação de um sistema industrializado fez com que eles superassem a inexperiência e a insegurança, deixando-os mais confiantes com relação ao resultado final.

Observando-se a condução da disciplina, percebe-se que embora o docente tenha aprovado a aplicabilidade de um sistema pré-fabricado no ensino de projeto, ele sentiu alguma dificuldade em conduzir a disciplina, o que, em 
algumas situações, aconteceu em função do descompasso entre as exigências acadêmicas e a quantidade de informações técnicas nos catálogos (e ausência de algumas especificações). Acredita-se, ainda, que haveria a possibilidade de se exigir mais dos estudantes com relação a outros aspectos do projeto, especialmente em termos conceituais ou mesmo no estudo de detalhes diferenciados, o que não aconteceu.

Verifica-se que o processo de ensino-aprendizagem do exercício se observado à luz da teoria, aponta para a necessidade de nós, enquanto docentes e pesquisadores, adotaram uma postura que permita ao aluno um envolvimento maior com o processo de concepção projetual, na medida em que o sistema construtivo seja cuidadosamente definido durante o processo. A possibilidade de um aluno desenvolver seu próprio sistema estrutural oferece ganhos reais à sua formação, pois exigirá que analise todos os aspectos que deverão ser considerados na hieraquização e seleção de soluções, bem como as implicações de cada solução.

Além disso, mesmo que o aluno não projete o sistema adotado na edificação, a escolha de um sistema mais flexível oferecerá uma variedade maior de possibilidades compositivas, em função de suas junções e encaixes, aspecto que deve ser considerado na seleção de um sistema pré-fabricado e desmontável para realização de novas experiências didáticas nesse campo.

\section{REFERÊNCIAS}

ALBUQUERQUE, G. L. A. O projeto de arquitetura de espaços temporários com uso de sistema construtivo remontável : um estudo exploratório. 2013. Tese. (Doutorado em Arquitetura e Urbanismo) - Universidade Federal do Rio Grande do Norte, Natal.

BOUDON, P., DESHAYES, P., POUSIN, F., SCHATZ, F. Enseigner la Conception Architecturale - Cours d'Architecturologie. Paris: Éditions de la Villlette, 2000.

BOUTINET, J. P. Antropologia do projeto. (Trad.) Porto Alegre: Artmed, 2002.

CATÁLOGO TÉCNICO SPRECH, 2011. Dados Técnicos do Sistema Arcostruttura. Disponível em: < http://www.sprech.com.br/>. Acesso em: 08 ago. 2014.

CORDIVIOLA, A. R. Notas sobre o saber projetar. Arquitextos/Vitruvius, n. 103, out. 2001. Disponível em <http://www.vitruvius.com.br/arquitextos/arq000/ esp103.asp>. Acesso em 20 abr. 2011.

KRAUSE, C. B. Ciência e Concepção Arquitetônica: reintegrando tecnologia e arquitetura. In: DEL RIO, V. (org.) Arquitetura Pesquisa \& Projeto. Rio de Janeiro: Pro Editores, 1998.

LAWSON, B. Como arquitetos e designers pensam. (Trad.) São Paulo: Oficina de Textos, 2011.

MAHFUZ, E. Ensaio sobre a razão compositiva. Belo Horizonte: UFV/AP Cultural, 1995.

NAVEIRO, R. M., OLIVEIRA, V. F. (org.). O Projeto de Engenharia, Arquitetura e Desenho Industrial: Conceitos, reflexões, aplicações e formação profissional. Juiz de Fora: Editora UFJF, 2001.

NEVES, L. P. Adoção do Partido na Arquitetura. Salvador: UFBA, 1998. 
ODEBRECHT, S. Projeto Arquitetônico: conteúdos técnicos básicos. Blumenau: Edifurb, 2006.

SILVA, E. Uma introdução ao Projeto Arquitetônico. 2 ed. Porto Alegre: UFRGS, 1998.

ZEIN, R. A síntese não é ponto de chegada, mas de partida. In: LARA, F., MARQUES, S. (org). Desafios e Conquistas da Pesquisa e do Ensino de projeto. Rio de Janeiro: Virtual Científica, 2003. 